\title{
Performance Evaluation: A Glimpse of Its Prominence in This Modern Globalised Economy
}

\author{
M. Subramanyiam Reddy ${ }^{a}$, and Dr. N. Rajendhiran ${ }^{b}$ \\ Research Scholar, Department of Management Studies, \\ Periyar University, Salem. \\ ${ }^{\text {b}}$ Rtd. Professor and Director, Department of Management Studies, \\ Periyar University, Salem.
}

Article History: Received: 11 January 2021; Accepted: 27 February 2021; Published online: 5 April 2021

\begin{abstract}
Nowadays, performance evaluation has become an inevitable factor in the field of all sectors. It has become a formal procedure in measuring the progress of employee's work scales. It is an important procedure in measuring the growth of work progress and it promotes the promotion of the employees. Performance evaluation helps in grading the employees annually and aids in salary raises. Further, it also enhances the quality of work progress, provides useful feedback regarding the work performed. This paper tries to investigate the importance of performance evaluation and its importance in the organisatinal sector. Further, this paper tries to underline the need for a performance evaluation system in the field of work in this present globalized technological world.
\end{abstract}

Keywords: Job progress, promotion, feedback, dual benefit

\section{Introduction}

Organisations depend on their employees for their growth. They are considered as an asset of the organisations. The human workforce has an extraordinary talent of creativity, productivity, problem-solving ability, etc. Besides, they further need strong motivation in order to evolve in their talent. The best motivational force can be provided to the employees through the performance evaluation process. A well-designed performance evaluation process helps in the growth of the employee and the organization on the whole towards greater achievement.

\section{Objectives of the study:}

- To comprehend the need for performance evaluation

- To understand the positive thread behind adopting performance evaluation

- To analysis the importance of feedback in the working sector

- To realize the role of an employee and an employer in the working circle.

By facilitating enhanced and better relationships, the performance evaluationapproach promotes a historical record of the events of the working community which in turn promotes massive professional growth. Khushbu S. Dave (2014, p. 264) states as,

The performance is measured against such factors as job knowledge, quality and quantity of output, initiative, leadership abilities, supervision, dependability, co-operation, judgment, versatility, and health. In any top-notch organization, not just in healthcare, performance appraisals are essential if the company is going to achieve its mission and ensure a competent staff and safe environment, for its external and internal customers.

\section{Ways to evaluate employee's performance include:}

- The quality of work they do

- Involvement of creativity in work progress

- Maintaining a consistent improvement

- Exhibiting leadership qualities

Performance evaluation helps in the effective fulfillment of the job and it also further contributes to attaining the goals of the organization. It also guides the employees in the accomplishment of their jobs. In order to enhance the outcome, the manager or the owner of the firm should take extra care in fulfilling certain needs, which includes,

- Awareness about different job nature

- Monitoring the behavior of the employees

- Tracking the goals of the work process

- Providing effective feedback towards the betterment of the work

- Kindling the process for effective work strategies

In this context, Khushbu S. Dave (2014, p. 364) states as, 
Performance appraisal is a process of summarizing assessing and developing work performance an employee. In order to be effective and constructive the performance manager should make every effort to obtain as much objective information about employee's performance as possible.

Through effective performance evaluation, the company or any sector may provide motivational and training programmes for effective growth progress. The major element or the key factor for a good performance elevation are:

- Purpose

- Teamwork

- Accountability

- Work progress

As a result, many organisational policies and practices are evolved which helps in the effective promotion of working temperaments. Through the performance evaluation process, effective feedback can be given which in turn promotes a healthy working nature. Leila Najafi and et al. (2011, p. 1762) quoted in (DeVoe and Iyengar, 2004) regarding the importance of feedback in performance evaluation as,

Feedback is an important component of performance appraisal. While positive feedback is easily accepted, negative feedback often meets with resistance unless it is objective, based on a credible source and given in a skilful manner.

Performance evaluation helps the managers in taking the decision, compensation, dismissal, promotion, etc. It also acts as a medium or a platform for the managers to act effectively for the betterment of the work environment. In order to reach the goals of any sector, performance evaluation helps handy. In this context, A Selvarasu (2014, p. 10) states "The Performance appraisal is one of the most important human resource management practices as it yields critical decisions integral to various human resource actions and outcomes".

Workers are evaluated on the basis of their performance in par with the certain prerequisites of the company. In addition, it also enhances the company to redefine the prerequisites as per the need of the changing modern society. It helps in understanding the standards of the employees and in turn, it helps them in judging their standards for improvement. Through this systematic assessment plan and process, the company can set its goal and evaluate the growth progress in a specific time. Individual employees' strength and weakness can be analysed in a better scale for the effective work growth.

\section{Performance evaluation- An effective developmental tool}

D. B. Bagul (2011, p. 288) defines performance evaluation in his research article as,

Performance Appraisal is a method of evaluating the behavior of employees in the work spot, normally including both the quantitative and qualitative aspects of job performance.Performance here refers to the degree of accomplishment of the tasks that make up an individual's job. It indicates how well an individual is fulfilling the job demands. Often the term is confused with effort, but performance is always measured in terms of results and not efforts

It has a dual benefit, it promotes development for both the employees and the company. It tries to measure the level of attainment of the employees in various outlooks namely one's job attainment, knowledge, quality and quantity of work progress, co-operation, leadership qualities, etc. Leila Najafi and et al. (2011, p. 1761) putforth their opinion regarding performance evaluation in the following words as,

Performance evaluation is a necessary and beneficial process, which provides annual feedback to staff members about job effectiveness and career guidance.Appraisal is an importantinstrument in the manpower management, if it is performed correctly and logically, it can conduct the organizations to their goal and the personnel will achieve their interests.

\section{Conclusion}

On the whole, it is clear that performance evaluation has an exemplifying impact on the growth of the company. It benefits both the job seekers and the job givers dually. Performance evaluation system suits best for all major sectors of the workforce. If this is applied and followed efficiently and effectively in the organisations, it may result in tremendous work progress. At the same time, organisations must take extra care to use it effectively for the betterment of all.

\section{References:}

1. A Selvarasu and Subbu Krishna Sastry. (2014), A Study of Impact on Performance Appraisal on Employee's Engagement in an Organization, International Journal of Managerial Studies and Research (IJMSR) Vol. 2, Iss. 11, pp. 10-22.

2. D. B. Bagul, (2014), A Research Paper On "Study Of Employee's Performance Appraisal System, Scholarly Research Journal For Humanity Science and English Language, Vol. 1, Iss. 2, pp. 287-292.

3. Dave S. Khushbu. (2014), Research Paper on Performance Appraisal of Nurses in Hospitals (With Specific Reference to Saurashtra Region), Management, Vol. 4, Iss. 5, pp. 364-366.

4. Kaur, Prabhjot and Walia, Kranti. (2015), Performance Evaluation of the Indian Banking Sector: A Study of Selected Commercial Banks, The IUP Journal of Bank Management, Vol. XIV, Iss. 2, pp. 38-48. 
5. Najafi, Leila and et al. (2011), Performance Evaluation and its Effects on Employees' Job Motivation in Hamedan City Health Centers, Australian Journal of Basic and Applied Sciences, Vol. 5, Iss. 12, pp. 1761-1765.

6. R. D. Arvey and K. R. Murphy. (1998). Performance Evaluation In Work Settings, Annu. Rev. Psychol, Vol. 49, pp. 141-168.

7. Shrivastava A. and Purang P. (2011), Employee perceptions of performance appraisals: a comparative study on Indian banks, The International Journal of Human Resource Management, Vol. 22, Iss. 3, pp. 632-647. 